\title{
SOCIO-DEMOGRAPHIC CHARACTERISTICS AFFECTING COMPLIANCE TO INTRA DERMAL RABIES VACCINATION AT ANTI RABIES CLINIC IN A GOVERNMENT TERTIARY CARE HOSPITAL IN KARNATAKA
}

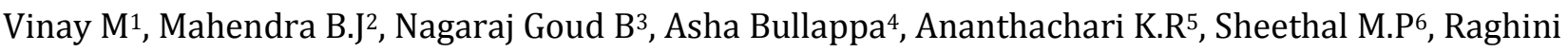
Ranganathan ${ }^{7}$, Anil Kumar ${ }^{8}$

\section{HOW TO CITE THIS ARTICLE:}

Vinay M, Mahendra BJ, Nagaraj Goud B, Asha Bullappa, Ananthachari KR, Sheethal MP, Raghini Ranganathan ${ }^{7}$, Anil Kumar. "Socio-demographic characteristics affecting compliance to intra dermal rabies vaccination at anti rabies clinic in a Government tertiary care hospital in Karnataka". Journal of Evolution of Medical and Dental Sciences 2013; Vol2, Issue 37, September 16; Page: 7090-7095.

BACKGROUND: Animal bite victims run the risk of contracting rabies, which is almost always fatal. Post Exposure Prophylaxis (PEP) effectively prevents the occurrence of rabies in the exposed persons. The Anti Rabies Clinic in the government hospital attached to Mandya Institute of Medical Sciences (ARC-MIMS) provides PEP to victims in and around Mandya.

\section{METHODOLOGY:}

\section{Objectives:}

1. To describe the sociodemographic profile of animal bite victims attending ARC-MIMS.

2. To determine the compliance to Intra Dermal Rabies Vaccination (IDRV) at ARC-MIMS.

3. To determine the socio demographic factors associated with compliance to IDRV

Study setting: Anti Rabies Clinic of Mandya Institute of Medical Sciences, Mandya.

Study period: One year (1-1-2012 to 31-12-12)

Study subjects: Animal bite victims reporting to ARC-MIMS.

Type of study: Descriptive study.

RESULTS: In the present study a total of 4264 animal bite victims were treated at the ARC-MIMS during the study period. There were 1017(23.9\%) category II and 3247(76.1\%) category III patients. The compliance for the $2^{\text {nd }}$ dose on day 3 was 3413 (84.7\%). 2552 (73.2\%) of the victims came for the $3^{\text {rd }}$ dose on the $7^{\text {th }}$ day and only 1492 (53.2\%) turned up on day 28 . The completion of the schedule was higher among females, patients aged more than 45 years, urban residents and those who had a college education. There was no statistically significant difference in compliance between those who had Below Poverty Line (BPL) card and those who did not. Compliance was significantly higher among those having category II exposure and re-exposure cases.

KEY WORDS: Intra-dermal Rabies Vaccine, Compliance, RIG, Sociodemographic factors.

INTRODUCTION: Rabies is a zoonotic disease is caused by Lyssavirus. Once a person develops signs and symptoms of Rabies, it is nearly always fatal. Rabies is a neglected disease of poor and vulnerable populations whose deaths are rarely reported ${ }^{1}$. Out of the annual 55,000 rabies deaths that occur globally, 20,000 deaths occur in India. Most of the human rabies deaths occur due to transmission of the virus by infected dogs.

The Indian Government has adopted its 'National Guidelines for Intradermal Vaccination' from World Health Organization guidelines. IDRV requires a smaller quantity 


\section{ORIGINAL ARTICLE}

of vaccine to be injected into the skin. It is $60-80 \%$ cheaper than vaccination by intramuscular route ${ }^{2}$. IDRV is also expected to increase the compliance due to lesser number of visits and decreased cost of the regimen ${ }^{3}$.

The Anti-Rabies Clinic at the Mandya Institute of Medical Sciences (ARC-MIMS) has been providing post exposure prophylaxis against rabies since 2007. Adherence to the stipulated dates and completion of the vaccination schedule is vital to prevent the disease post-exposure. Various studies on compliance have shown that the percentage of completion of the regimen varies between $35.3 \%$ and $75.5 \% 4,5,6$. The present study tries to identify the socio-demographic factors which influence the compliance to IDRV.

Objectives: The present study was conducted

1. To describe the sociodemographic profile of animal bite victims attending ARC-MIMS.

2. To determine the compliance to IDRV at ARC- MIMS.

3. To determine the socio demographic factors associated with compliance to IDRV

METHODOLOGY: The present study is a retrospective record based study carried out at the ARCMIMS where patients were provided IDRV (Updated Thai Cross regimen) for post-exposure prophylaxis. The records maintained at ARC-MIMS from 1st January 2012 to 31st December 2012 were analyzed.

The patients were categorized based on their compliance with respect to completion of one, two, three and four doses. Compliance of patients having different socio-demographic characteristics was analyzed. The socio-economic characteristics that were considered were age, sex, place of residence, education and economic status. Compliance among the patients with different categories of exposure, immunoglobulin acceptors and re-exposure victims was also analyzed.

Compliance rates were expressed in percentage. The association between compliance and different sociodemographic factors were ascertained using chi-square test. Z test for proportions was used to ascertain the difference in compliance between the post-exposure and re-exposure cases.

RESULTS AND DISCUSSION: A total of 4401 animal bite victims were treated at ARC-MIMS during the study period. 4264 patients received post-exposure prophylaxis and 137 patients received booster doses in the event of re-exposure. The first dose of IDRV is given on the first day of the visit and they were advised to return on days 3,7 and 28 to complete the immunization schedule. In case of re-exposure prophylaxis 2 doses are administered on day 0 and day 3

\begin{tabular}{|c|c|c|c|c|c|c|c|c|}
\hline \multicolumn{2}{|c|}{} & 1 dose & $\begin{array}{c}2 \\
\text { doses }\end{array}$ & $\begin{array}{c}3 \\
\text { doses }\end{array}$ & $\begin{array}{c}4 \\
\text { doses }\end{array}$ & Total & $\begin{array}{c}\text { Chi } \\
\text { squared } \\
\text { value }\end{array}$ & P value \\
\hline \multirow{3}{*}{ Sex } & Male & $\begin{array}{c}523 \\
(18.0 *\end{array}$ & $\begin{array}{c}333 \\
(11.5)\end{array}$ & $\begin{array}{c}620 \\
(21.4)\end{array}$ & $\begin{array}{c}1427 \\
(49.2)\end{array}$ & $\begin{array}{c}2903 \\
(68.1)\end{array}$ & \multirow{2}{*}{80.93} & $<0.0001$ \\
\cline { 2 - 8 } & Female & $\begin{array}{c}129 \\
(9.5)\end{array}$ & $\begin{array}{c}158 \\
(11.6)\end{array}$ & $\begin{array}{c}232 \\
(17.0)\end{array}$ & $\begin{array}{c}842 \\
(61.9)\end{array}$ & $\begin{array}{c}1361 \\
(31.9)\end{array}$ & & \\
\hline Age & $<15$ & 211 & 157 & 287 & 857 & 1512 & 112.7 & $<0.0001$ \\
\hline
\end{tabular}


ORIGINAL ARTICLE

\begin{tabular}{|c|c|c|c|c|c|c|c|c|}
\hline & & (14) & $(10.4)$ & $(19.0)$ & $(56.7)$ & $(35.5)$ & & \\
\hline & $15-45$ & $\begin{array}{c}340 \\
(17.8)\end{array}$ & $\begin{array}{c}271 \\
(14.2)\end{array}$ & $\begin{array}{c}440 \\
(23.0)\end{array}$ & $\begin{array}{c}861 \\
(45.0)\end{array}$ & $\begin{array}{c}1912 \\
(44.8)\end{array}$ & & \\
\hline & $>45$ & $\begin{array}{l}101 \\
(12)\end{array}$ & $\begin{array}{c}63 \\
(7.5)\end{array}$ & $\begin{array}{c}125 \\
(14.9)\end{array}$ & $\begin{array}{c}551 \\
(65.6)\end{array}$ & $\begin{array}{c}840 \\
(19.7)\end{array}$ & & \\
\hline \multirow{2}{*}{ Residence } & Urban & $\begin{array}{c}76 \\
(8.3)\end{array}$ & $\begin{array}{c}43 \\
(4.7)\end{array}$ & $\begin{array}{c}115 \\
(12.6)\end{array}$ & $\begin{array}{c}680 \\
(74.4)\end{array}$ & $\begin{array}{c}914 \\
(21.4)\end{array}$ & \multirow{2}{*}{213.9} & \multirow{2}{*}{0.000} \\
\hline & Rural & $\begin{array}{c}576 \\
(17.2) \\
\end{array}$ & $\begin{array}{c}448 \\
(13.4) \\
\end{array}$ & $\begin{array}{l}737 \\
(22) \\
\end{array}$ & $\begin{array}{c}1589 \\
(47.4) \\
\end{array}$ & $\begin{array}{c}3350 \\
(78.6)\end{array}$ & & \\
\hline \multirow{2}{*}{$\begin{array}{l}\text { Economic } \\
\text { status }\end{array}$} & $\begin{array}{c}\text { Below poverty } \\
\text { line(BPL) }\end{array}$ & $\begin{array}{c}269 \\
(16.2)\end{array}$ & $\begin{array}{c}199 \\
(11.9)\end{array}$ & $\begin{array}{c}327 \\
(19.7)\end{array}$ & $\begin{array}{c}865 \\
(52.1)\end{array}$ & $\begin{array}{c}1660 \\
(38.9)\end{array}$ & \multirow{2}{*}{2.745} & \multirow{2}{*}{0.4325} \\
\hline & $\begin{array}{l}\text { Above poverty } \\
\text { line(APL) }\end{array}$ & $\begin{array}{c}383 \\
(14.7)\end{array}$ & $\begin{array}{c}292 \\
(11.2)\end{array}$ & $\begin{array}{c}525 \\
(20.2)\end{array}$ & $\begin{array}{c}1404 \\
(53.9)\end{array}$ & $\begin{array}{c}2604 \\
(61.1)\end{array}$ & & \\
\hline \multirow{4}{*}{ Education } & Illiterate & $\begin{array}{c}282 \\
(18.8)\end{array}$ & $\begin{array}{c}225 \\
(15.0)\end{array}$ & $\begin{array}{c}322 \\
(21.5)\end{array}$ & $\begin{array}{c}668 \\
(44.6)\end{array}$ & $\begin{array}{c}1497 \\
(35.1)\end{array}$ & \multirow{4}{*}{122.3} & \multirow{4}{*}{$<0.001$} \\
\hline & Primary & $\begin{array}{c}174 \\
(14.7)\end{array}$ & $\begin{array}{c}146 \\
(12.4)\end{array}$ & $\begin{array}{c}230 \\
(19.5)\end{array}$ & $\begin{array}{c}631 \\
(53.4)\end{array}$ & $\begin{array}{c}1181 \\
(27.7)\end{array}$ & & \\
\hline & High school & $\begin{array}{c}120 \\
(13.2)\end{array}$ & $\begin{array}{c}94 \\
(10.4)\end{array}$ & $\begin{array}{c}169 \\
(18.6)\end{array}$ & $\begin{array}{c}524 \\
(57.8)\end{array}$ & $\begin{array}{c}907 \\
(21.3)\end{array}$ & & \\
\hline & College & $\begin{array}{c}76 \\
(11.2)\end{array}$ & $\begin{array}{c}26 \\
(3.8)\end{array}$ & $\begin{array}{c}131 \\
(19.3)\end{array}$ & $\begin{array}{c}446 \\
(65.7)\end{array}$ & $\begin{array}{c}679 \\
(15.9)\end{array}$ & & \\
\hline \multicolumn{2}{|c|}{ Total } & $\begin{array}{c}652 \\
(15.3)\end{array}$ & $\begin{array}{c}491 \\
(11.5)\end{array}$ & $\begin{array}{c}852 \\
(20.0)\end{array}$ & $\begin{array}{c}2269 \\
(53.2)\end{array}$ & 4264 & & \\
\hline
\end{tabular}

Table no. 1: Association between compliance and age, sex, place of residence, economic status \& educational status in patients who received IDRV

*Figures in parentheses indicate percentages

Out of the 4264 patients who received IDRV, 68.1\% were males and $31.9 \%$ were females. Majority (44.8\%) of the patients belonged to the age group of 15-45 years followed by less than 15 years of age (35.5\%) and more than 45 years of age (19.7\%). A large proportion of the patients were rural residents (78.6\%). 38.9\% of the patients had BPL card and $61.1 \%$ did not possess a BPL card. $35.1 \%$ of the patients were illiterates, $27.7 \%$ had received primary education, $21.3 \%$ had high school education and only $15.7 \%$ had college education.

It was observed that $53.2 \%$ completed the prescribed four dose schedule. Out of the 4264 patients $852(20.0 \%)$ completed 3 doses and did not receive the fourth dose. $11.5 \%$ of the 4264 patients received only two doses. 654 (15.3\%) out of the 4264 patients received only the first dose and did not turn up for the follow up visits.

Though majority $(68.1 \%)$ of the animal bite victims were males, a greater proportion of the females (61.9\%) completed the schedule compared to $49.2 \%$ of males who completed the schedule. The difference in completion of schedule between males and females was statistically significant $(\mathrm{p}<0.001)$. This is similar to the results reported by Mohammedali et al, where males tended to default more often than the females. ${ }^{6}$

Majority of the animal bite victims belonged to the age group 15-45 years of age (44.8\%) and the compliance was least (45.0\%) in the same age group. The compliance was highest $(65.6 \%)$ in the patients aged more than 45 years followed by those $<15$ years of age $(56.7 \%)$. The compliance was 
lowest in the age group 15-45 years possibly because they are also the working age group. The difference in compliance between these age groups was statistically significant.

The patients who received IDRV were mostly from rural areas (78.6\%). However more urban dwellers (74.4\%) completed the schedule when compared to the rural dwellers (47.4\%). The difference was statistically significant and is possibly due to proximity of the clinic to the urban dwellers.

There was no statistically significant difference in compliance between the economic groups below poverty line $(52.1 \%)$ and above the poverty line (53.9\%). This is possibly due to the subsidized rates of vaccine for the patients who hold a below the poverty line card.

The patients who had attended college had the highest compliance rates $(65.7 \%)$, followed by those patients who had completed high school education (57.8\%). The compliance among patients who had completed primary education and illiterates were $53.4 \%$ and $44.6 \%$ respectively. There was a significant difference in compliance between the patients having different educational status. Better the education, higher was the compliance.

The compliance among patients with category II bite (71.6\%) was higher than patients with category III bite $(47.5 \%)$. The difference in completion of the fourth dose was statistically significant. In the study conducted by Mohammedali et al, there was no statistically significant difference in compliance between the patients with category II and category III exposures ${ }^{6}$.

Among the patients who had category III bite, only $14.0 \%$ had received Rabies immunoglobulin (RIG). The patients who received RIG had a higher completion rate (59.8\%) when compared to those who did not receive RIG (45.5\%) and this difference was statistically significant.

The completion rate for re-exposure cases ( 2 doses) was $70.8 \%$ compared to $53.2 \%$ among those who received IDRV for the first time (4 doses). The difference was statistically significant.

\begin{tabular}{|c|c|c|c|c|c|c|}
\hline & 1 Dose & 2 Doses & 3 Doses & 4 Doses & Total & P value \\
\hline Category II & 113(11.1)* & $66(6.5)$ & $110(10.8)$ & $728(71.6)$ & 1017 & \multirow{2}{*}{$<0.001$} \\
\hline Category III & $539(16.6)$ & $425(13.1)$ & $742(22.9)$ & $1541(47.5)$ & 3247 & \\
\hline $\begin{array}{l}\text { RIG non } \\
\text { recipients }\end{array}$ & $459(16.4)$ & $391(14.0)$ & $673(24.1)$ & $1269(45.5)$ & 2792 & \multirow[t]{2}{*}{$<0.001$} \\
\hline RIG recipients & $80(17.6)$ & $34(7.5)$ & $69(15.16)$ & $272(59.8)$ & 455 & \\
\hline $\begin{array}{l}\text { Re-exposure } \\
\text { cases }\end{array}$ & $40(29.2)$ & $97(70.8)$ & $\mathrm{NA}^{\dagger}$ & NA & 137 & $<0.0001$ \\
\hline
\end{tabular}

*Figures in parentheses indicate percentages ${ }^{+} \mathrm{NA}-$ Not applicable

Limitations: Some patients received the first dose of the vaccine and Rabies immunoglobulin and informed that they would take the rest of the doses at a government facility which offers IDRV close to their residence. These patients were not included in the statistical analysis. Some patients did not turn up for the last visit because the bite was a provoked bite by a vaccinated healthy pet animal. The proportion of patients who did not turn up for these reasons could not be determined. 


\section{ORIGINAL ARTICLE}

CONCLUSION: The analysis of the sociodemographic profile of the patients who attended ARC-MIMS in 2012 showed that most of them were males, the proportion of patients aged between 15-45 years was higher, many were rural residents and did not have a BPL card.

The completion rate for post exposure prophylaxis was 53.2\%. The completion of the schedule was higher among females, patients aged more than 45 years, urban residents and those who had college education. There was no statistically significant difference in completion rates between those who had BPL card and those who didn't.

Compliance was higher among patients who had category II bite, RIG recipients and those who received re-exposure prophylaxis.

ACKNOWLEDGEMENT: The authors sincerely thank all the faculty of the department, the Interns and the staff of the ARC for their cooperation and support in this study. The authors are grateful to the patients who attended ARC-MIMS and participated in this study.

\section{REFERENCES:}

1. World Health Organization. Fact sheet on Rabies. Available at "http://www.who.int/mediacentre/factsheets/fs099/en/" Accessed on 6/6/2013 at 5:15 pm.

2. World Health Organization. India's ongoing war against rabies. Bulletin of the World Health Organization. 2009, Vol 87(12) ; 885-964

3. Omesh Kumar Bharti OK, Wim Van Damme WV, Decoster K, Isaakidis P, Appelmans A, Ramachandran $\mathrm{V}$ et al. Breaking the Barriers to Access a Low Cost Intra-Dermal Rabies Vaccine through Innovative "Pooling Strategy". World Journal of Vaccines, 2012, 2, 121-124.

4. Vinay M, Mahendra BJ. Compliance to Intra Dermal Rabies Vaccination Schedule (Updated Thai Red Cross) at the Anti Rabies Clinic, Mandya Institute of Medical Sciences Hospital, Mandya, Karnataka State. APCRI Journal: Vol 12(1);July 2011; 35 7

5. Mahendra BJ, Harish BR, Vinay M. A Study of Factors influencing compliance to IDRV at Anti-Rabies Clinic of Mandya Institute of Medical Sciences, Mandya. APCRI Journal: Vol 11(1) July 2009; 18-20

6. Mohammedali JM, Martin J, Bina T, Raphel L, Lailabi, Jayadev .Compliance to IDRV at the Anti Rabies Clinic in a Tertiary Care Hospital in Northern Kerala. APCRI Journal: Vol 12(2); July $2011 ; 21-4$ 


\section{ORIGINAL ARTICLE}

\section{AUTHORS:}

1. Vinay M.

2. Mahendra B.J.

3. Nagaraj Goud B.

4. Asha Bullappa

5. Ananthachari K.R.

6. Sheethal M.P.

7. Raghini Ranganathan

8. Anil Kumar

\section{PARTICULARS OF CONTRIBUTORS:}

1. Associate Professor, Department of Community Medicine, Mandya Institute of Medical Sciences.

2. Professor and Head, Department of Community Medicine, Mandya Institute of Medical Sciences.

3. Assistant Professor and Statistician, Department of Community Medicine, Mandya Institute of Medical Sciences.

4. Post Graduate Student, Department of Community Medicine, Mandya Institute of Medical Sciences.
5. Post Graduate Student, Department of Community Medicine, Mandya Institute of Medical Sciences.

6. Post Graduate Student, Department of Community Medicine, Mandya Institute of Medical Sciences.

7. Post Graduate Student, Department of Community Medicine, Mandya Institute of Medical Sciences.

8. Tutor, Department of Community Medicine, Mandya Institute of Medical Sciences.

\section{NAME ADDRESS EMAIL ID OF THE}

\section{CORRESPONDING AUTHOR:}

Dr. Raghini Ranganathan,

Department of Community Medicine,

Mandya Institute of Medical Sciences,

Mandya - 571401.

Email-raghinister@gmail.com

Date of Submission: 05/09/2013.

Date of Peer Review: 06/09/2013.

Date of Acceptance: 10/09/2013.

Date of Publishing: 12/09/2013 